|| ISSN(online): 2589-8698 || ISSN(print): 2589-868X || International Journal of Medical and Biomedical Studies

Available Online at www.ijmbs.info

PubMed (National Library of Medicine ID: 101738825)

Index Copernicus Value 2018: 75.71

Volume 3, Issue 4; April: 2019; Page No. 01-04

\title{
KNOWLEDGE, ATTITUDE AND PRACTICES RELATED TO CERVICAL CANCER.
}

\author{
Kavita Agarwal ${ }^{1}$, Saroj Paliwal ${ }^{2}$ \\ ${ }^{1}$ M S Gyan \& Obst., Consultant Gynaecologist \\ ${ }^{2}$ M S Gyan \& Obst., Consultant Gynaecologist \\ ${ }^{1}$ Pratik Hospital and Research Center Bhilwara.
}

Article Info: Received 18 February 2019; Accepted 30 March. 2019

Cite this article as: Agarwal, K., \& Paliwal, S. (2019). KNOWLEDGE, ATTITUDE AND PRACTICES RELATED TO CERVICAL CANCER. International Journal of Medical and Biomedical Studies, 3(4).

DOI: https://doi.org/10.32553/ijmbs.v3i4.179

Address for Correspondence: Saroj Paliwal, M S Gyan \& Obst., Consultant Gynaecologist

Conflict of interest: No conflict of interest.

\section{Abstract}

Background: Cervical cancer is a malignant neoplasm arising from cells originating in cervix uteri. It may be completely asymptomatic in early stages.

Material and Methods: A facility based cross sectional study was done 200 women of reproductive age group (15-45 years) who present to out-patient department in gynecology.

Results: A total of 200 women are approached for interview, in which $182(91.00 \%)$ had not heard about cervical cancer, only $9.00 \%$ women had knowledge about cervical cancer. About $82.00 \%$ women had positive attitude about cervical cancer screening \& it's vaccine.

Conclusions: Women need more information about cervical cancer risk factors, symptoms and screening program.

Keywords: Cervical cancer, awareness, screening.

\section{Introduction:}

Cervical cancer is the third most common cancer among women and the fourth leading cause of cancer deaths in females worldwide. More than $85 \%$ of these cases and deaths occur in developing countries. India, accounts for $15.2 \%$ of the total cervical cancer deaths. ${ }^{1}$

Cervical cancer is a malignant neoplasm arising from cells originating in cervix uteri. It may be completely asymptomatic in early stages. ${ }^{2}$ In advanced stages it may present as persistent pelvic pain, unexplained weight loss, bleeding between periods, unusual vaginal discharge, bleeding between periods, unusual vaginal discharge, bleeding and pain after sexual intercourse. $^{3}$
Infection with Human Papilloma virus(HPV) types 16 and 18 cause $75 \%$ of cervical cancer globally . The other risk factors include tobacco consumption, multiple sexual partners, early age of sexual intercourse, increasing parity, prolonged use of oral contraceptive pills, sexually transmitted diseases. ${ }^{5}$

Kwown predisposing factors for cervical cancer include early age at first sexual intercourse, multiple sexual partners, smoking and women are immunosuppressed.

Primary prevention of cervical cancer aims at reducing the incidence of cervical cancer by controlling the cause and risk factors. The largest gain in reducing cervical cancer incidence and mortility by PAP Smear screening as a gold 
standard method of cervical cancer screening. Vaccine against some HPV provide effective protection ${ }^{6}$.

\section{Material and Methods}

Study Design: Cross sectional study-hospital based

Study Population: Women reproductive age group (15 -45 years)

Study Participants: The source population was all child bearing women whose age ranged from 15 to 45 years. The study population was WCBA (15-45 years) who had the chance of being randomly selected from the source population at a hospital level. We excluded women who had any serious illness during data collection and who are less than 18 years from the study.

Data Collection: Pretested structured questionnaire was used to collect data from each study subject. The questionnaire was adapted from related literatures ${ }^{6}$ with slight modification in line with the objectives of this particular study and to fit to the local context. Data collection was conducted through face to face interview. The questionnaire was completed after obtaining verbal consent from the participants. The completed questionnaires were collected on a daily bases to check for its consistency and completeness.

Data Analysis: After entering data into Excel worksheet, it was analyzed with the help of frequency, proportion, mean, standard deviation and tests of significance wherever applicable. Chi-square test was used for $p$-value calculation. If $p$-value $<0.05$ was significant and $>0.05$ was non-significant.

\section{Observations}

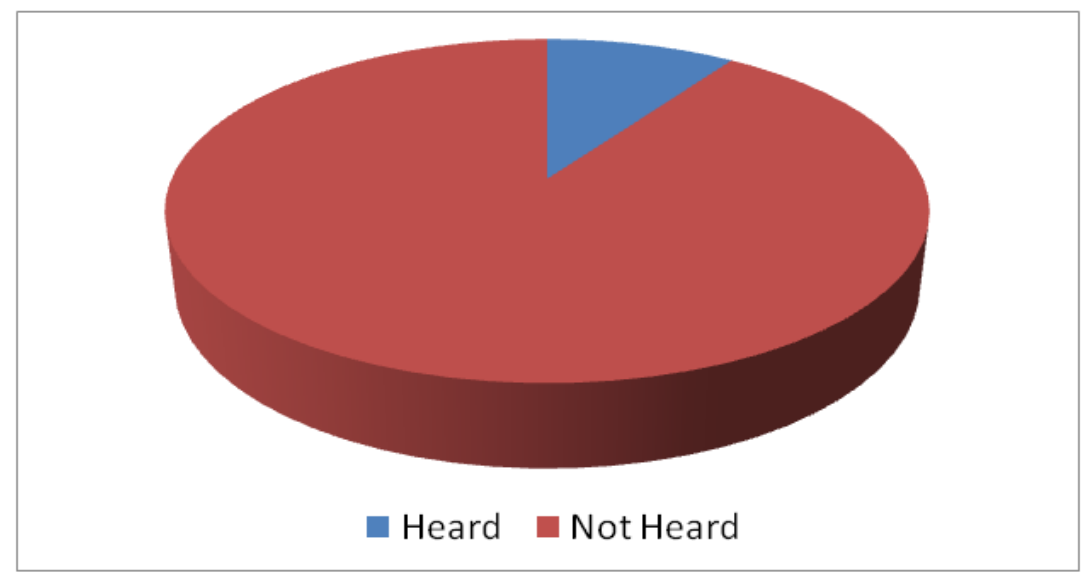

Figure 1: Knowledge about cervical cancer

Most of women 182(91\%) was not heard about cervical cancer, only 18 (9\%) women had knowledge about cervical cancer.

Table 1: Knowledge about Risk factors $(n=18)$

\begin{tabular}{|l|l|l|}
\hline Risk factor & Respondent & Percentage \\
\hline Family history & 5 & $27.78 \%$ \\
\hline Early stage coitus & 2 & $16.67 \%$ \\
\hline Multiple sex partner & 4 & $22.22 \%$ \\
\hline Smoking & 1 & $5.56 \%$ \\
\hline Cause by some infection & 6 & $33.33 \%$ \\
\hline
\end{tabular}

Out of 18 women who had knowledge about cervical cancer $33.33 \%$ women knew that infection is risk factor. 
Table 2: Knowledge about Symptoms $(n=18)$

\begin{tabular}{|l|l|l|}
\hline Symptoms & Respondent & Percentage \\
\hline Post coital bleeding & 4 & $22.22 \%$ \\
\hline Bleeding between menses & 5 & $27.78 \%$ \\
\hline Foul smelling vaginal discharge & 8 & $44.44 \%$ \\
\hline
\end{tabular}

Out of 18 women who had knowledge about cervical cancer $44.44 \%$ women knew that foul smelling is risk symptoms.

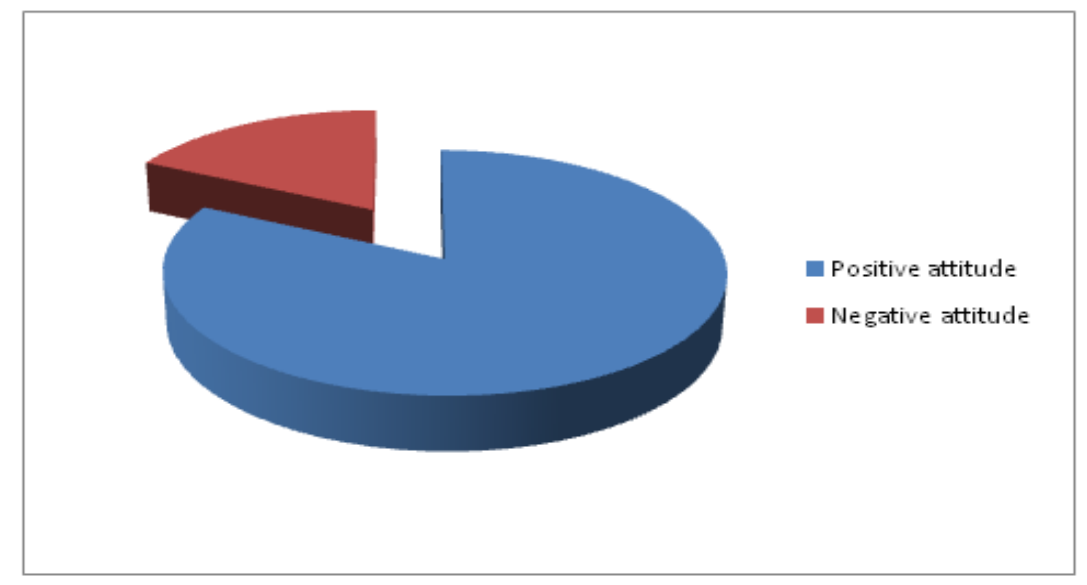

Figure 2: Attitude about Cervical Cancer

82.00\% women had positive attitude and $18.00 \%$ women had negative attitude about cervical cancer screening \& it's vaccine.

\section{Discussion}

The present study explored the KAP among women who are attending obstetrics and gynecology department of tertiary care referral hospital. among 200 respondents, most of them were illiterate, farmers, homemakers, and low economic status group. It is not uncommon, even in the $21^{\text {st }}$ century also the era will continue to find young women with little formal education and no training who are homemakers with children.

The study found that more than three fourth of population never heard about cervical cancer which is similar with results of studies conducted in developing and underdeveloped countries by Anorlu and Yifru and Asheber. ${ }^{7,8}$ However, these results are contrast with a study conducted by Chande HM et al. ${ }^{9}$ show more than threequarters of population are heard about cervical cancer.
Out of 18 women who had knowledge about cervical cancer $33.33 \%$ women knew that infection is risk factor in our study. This is consistent with findings from a similar study conducted in Northern Uganda by Mukama et al. $^{10}$

Still there is a lack of awareness about cervical cancer in women residing at rural area, where there is a need to conduct campaigns to improve their knowledge regarding symptoms, risk factors, and preventive measures. Women who are aware about cervical cancer they are more likely to take up measures of prevention by seeking medical attention and early screening ${ }^{11}$.

In this study $82.00 \%$ women had positive attitude and $18.00 \%$ women had negative attitude about cervical cancer screening \& it's vaccine. Some studies report that even providing of screening opportunities to women may not be utilized well due to some barriers such as fear of 
positive cervical cancer diagnosis, fear of cervical screening, and vaginal examination. ${ }^{12}$ Continuous conducting of cervical cancer awareness program will bring change in the attitude and perception of women toward cervical cancer screening.

\section{Conclusion}

Women need more information about cervical cancer risk factors, symptoms and screening program. The universal literacy program in the country has helped to improve the knowledge of cervical cancer prevention and reduce the exposure to various risk factors in the younger populations.It's major needs to involve multimedia, print-media, medical persons even ASHA, Anganwadi workers, teachers for awareness about cervical cancer screening.

\section{Bibliography}

1. Varughese J, Richman S. Cancer care inequity for women in resource-poo countries. Rev Obstet Gynecol 2010;3:12232.

2. Sathiyalatha $S$, Hemavathy $V$, Vijayalakshmi R. Cervical cancer kills one Indian woman every 7 minutes. Int J Innov Res Dev 2015;4:132-4.

3. Sharma A, Kulkarni $V$, Bhaskaran $U$, Singha M, Mujtahedi S, Chatrath A, et al. Profile of cervical cancer patients attending Tertiary Care Hospitals of Mangalore, Karnataka: A 4 year retrospective study. J Nat Sci Biol Med 2017;8:125-9.

4. Mishra GA, Pimple SA, Shastri SS. An overview of prevention and early detection of cervical cancers. Indian J Med Paediatr Oncol,2011;32:125-32.
5. Kaarthigeyan K. Cervical cancer in India and HPV vaccination. Indian J Med Paediatr Oncol 2012;33:7-12.

6. McPartland TS, Weaver BA, Lee SK, Koutsky LA. Men's perceptions and knowledge of human papillomavirus (HPV) infection and cervical cancer. J Am Coll Health 2005;53:225-30.

7. Anorlu RI. Cervical cancer: The sub-Saharan African perspective. Reprod Health Matters 2008;16:41-9.

8. Yifru T, Asheber G. Knowledge, attitude and practice of screening for carcinoma of the cervix among reproductive health clients at three teaching hospitals, Addis Ababa, Ethiopia. Ethiop J Reprod Health 2008;2:1-6.

9. Chande HM, Kassim T. Assessment of women's knowledge and attitude towards carcinoma of the cervix in Ilala Municipality. East Afr J Public Health 2010;7:74-7.

10. Mukama T, Ndejjo R, Musabyimana A, Halage AA, Musoke D. Women's knowledge and attitudes towards cervical cancer prevention: A cross sectional study in Eastern Uganda. BMC Womens Health 2017;17:9.

11. Mutyaba T, Faxelid E, Mirembe F, Weiderpass E. Influences on uptake of reproductive health services in Nsangi community of Uganda and their implications for cervical cancer screening. Reprod Health 2007;4:4.

12. Control of cancer of the cervix uteri. A WHO meeting. Bull World Health Organ 1986;64: 607-18. 